\title{
Comparison of the results of mathematical modeling of a GTM 120 miniature turbine jet engine with the research results
}

The paper presents gas-dynamic calculations of a GTM 120 miniature turbine jet engine. The engine performance parameters have been determined and then validated with theory contained in literature as well as the results of research carried out on a laboratory test stand.

Key words: miniature jet engine, jet engine

\section{Introduction}

Airplane model jet engines are becoming increasingly popular and recognized in the community of model makers as their primary objective is to make their models possibly close to the original and they are reluctant to apply conventional propellers in jet plane models. Unfortunately, high velocities of flying models fitted with jet engines lead to their relatively frequent crashes and that, in turn, renders airplane model engine manufacturers less eager in their attempts to extend the engine life. Despite the above, one can observe a continuous advancement in this type of drivetrains and its increasingly wider application. One of the examples of miniature turbine jet engines is a GTM 120 engine of Polish design.

The aim of the study was the performance of gasdynamic calculations of a GTM 120 miniature turbine jet engine, the determination of its parameters and then their comparison with theory contained in literature and the results of investigations carried out in a laboratory.

\section{GTM 120 design}

GTM 120 is a turbojet engine designed for subsonic airplane models. It is fitted with an non-adjustable intake and a single stage radial compressor (Fig. 1).

It has an axial combustor and a single stage axial turbine. The engine outlet nozzle is non-adjustable. The engine shaft is supported on two ceramic bearings. The engine start is carried out with an electric motor fitted before the intake. The engine is mainly designed for use in flying models but it can also be used as a didactic tool.

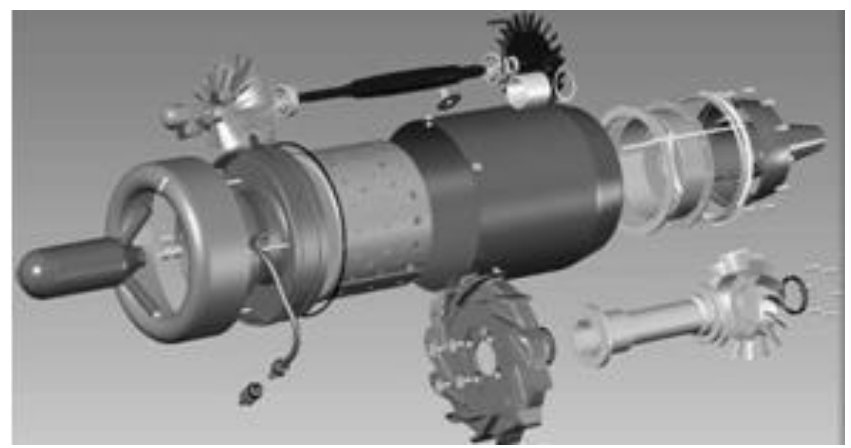

Fig. 1. GTM-120 engine [8]
The main priority when designing this engine was its simplicity of design and unification of components. This is confirmed by the centrifugal compressor and the turbine rotor (ready made subassemblies available at other manufacturers) as well as the non-adjustable intake and the outlet system.

\section{Reproduction of the GTM 120 turbine engine cycle parameters with the analytical method}

The gas-dynamic calculations can be divided into two stages [3].

The first, also referred to as preliminary gas-dynamic calculations includes the calculation or selection of the basic parameters of the cycle (compression rate of the compressor and temperature of the gas upstream of the turbine), determination of the engine mass flow rate that ensures an obtainment of the preset thrust as well as a preliminary selection of the flow channel dimensions.

The second, referred to as, as detailed gas-dynamic calculations trims the results of the preliminary calculations. At this stage the parameters are finally set in individual characteristic flow channel cross-sections (Fig. 2) as well as its final shape and size.

Because the task of the authors was to reproduce the parameters of the cycle of an existing engine, the first stage was modified. In order to accurately reproduce the GTM engine cycle parameters, these quantities were measured during the tests and then adopted as output ones for the preliminary gas-dynamic calculations in individual crosssections of the engine. As the calculation engine operating point, the authors chose the engine speed at which the engine produced the greatest specific thrust.

The outstanding parameters were assumed based on the data contained in the literature $[1,3]$.

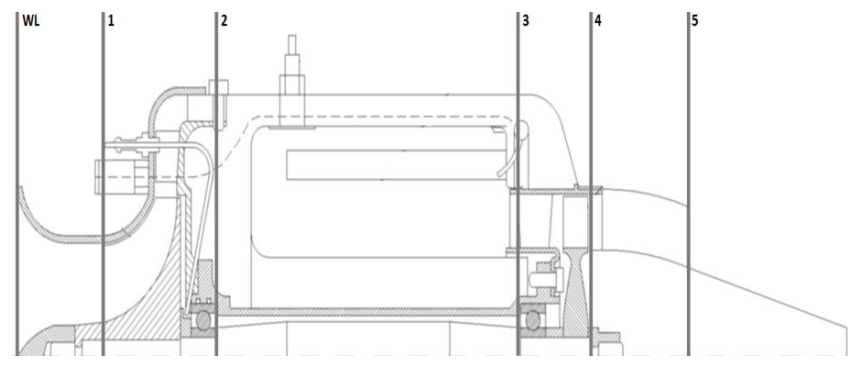

Fig. 2. Diagram of the jet engine with marked stations [5] 
The results of the calculations have been shown in the form of a curve of parameters changes in individual crosssections of the engine (Fig. 3). The curve made based on the performed investigations has the same character as the reference one, shown e.g. in [2], which confirms that the calculations are correct. Validation and discussion of the results has been presented in the further part of this paper.

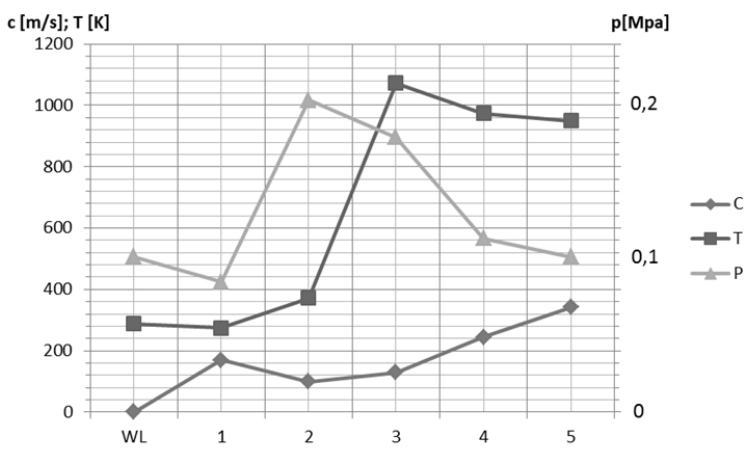

Fig. 3. Aerothermodynamic parameters in characteristic stations

\section{Reproduction of the GTM 120 turbine jet engine cycle parameters with the GasTurb software}

GasTurb provides a possibility of a quick and simple creation of models of different engines and determining their operating parameters. The obtained engine model can be freely modified, checking which setting would optimize the engine operation. With the use of the said software, it is possible to generate engine thermodynamic cycles as well as many characteristics describing the changes of selected parameters during the simulated engine operation. Using the obtained data, one can evaluate the differences among individual engine types, examine the impact of the surroundings on the engine operation etc.

Because of the fact that the analytical calculations were made for stationary conditions on the ground, according to ISA, also in the GasTurb software, a model reproducing the same conditions was developed.

During in-depth analyses within the software, a specially prepared compressor characteristics was implemented.

The eventually generated engine model produces a usable torque of $\mathrm{K}=0.08 \mathrm{kN}$ and has a specific fuel consumption on the level of $\mathrm{C}_{\mathrm{j}}=60.32 \mathrm{~g} /(\mathrm{kN} \cdot \mathrm{s})$. The second-bysecond fuel consumption is $\mathrm{C}_{\mathrm{s}}=0.00454 \mathrm{~kg} / \mathrm{s}$. The area of the outlet cross-section is $\mathrm{A}_{8}=0.0019 \mathrm{~m}^{2}$.

The changes of selected parameters of the working medium alongside the working channel have been shown in Fig. 4.

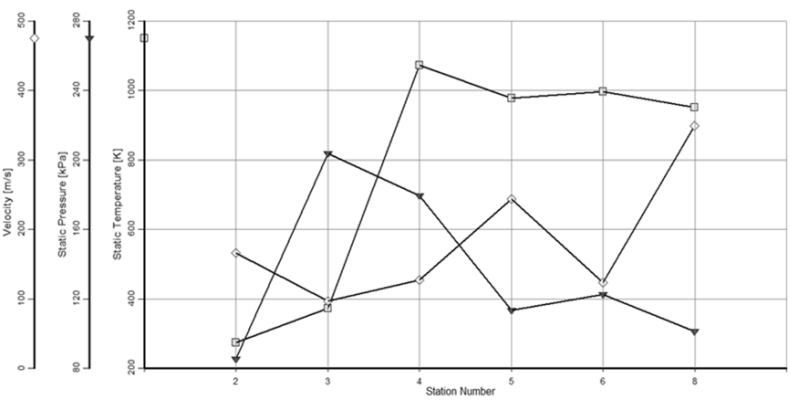

Fig. 4. Aerothermodynamic parameters in the characteristic stations
In the analytical calculations there are 5 characteristic cross-sections, while the GasTurb assumes 8 of them. Fig. 5 presents a diagram of the engine with the GasTurb software cross-sections marked.

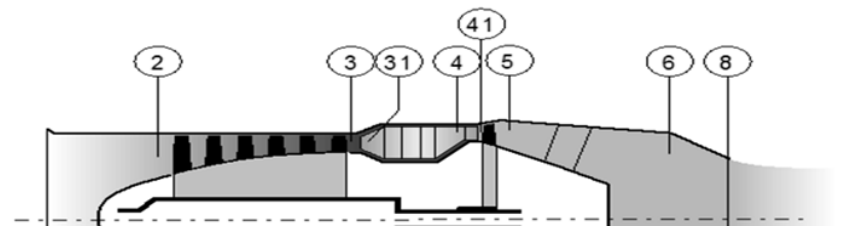

Fig. 5. Characteristic stations in the GasTurb software [7]

\section{Research of the GTM 120 turbine jet engine}

The investigations that the authors relied on, were carried out during the test of the GTM 120 engine throughout several measurement sessions. The GTM 120 engine parameters were recorded at different rotational speeds. During the tests, the following parameters were recorded: temperature, pressure, thrust, fuel consumption and engine speed.

During the tests, mass flow in the intake was determined using the Venturi tube.

The measured value also allowed calculating the engine specific parameters (specific thrust and specific fuel consumption). In order to compare the results of the investigations, they were converged to reduced parameters with the help of appropriate formulas. Then, they were put in tables and, on this basis, curves of the measured changes and calculated parameters were created depending on the engine rotational speed (test stand characteristics (Fig. 6 and 7). On their basis, the selection of the operating point was made for the aerothermodynamic calculations.

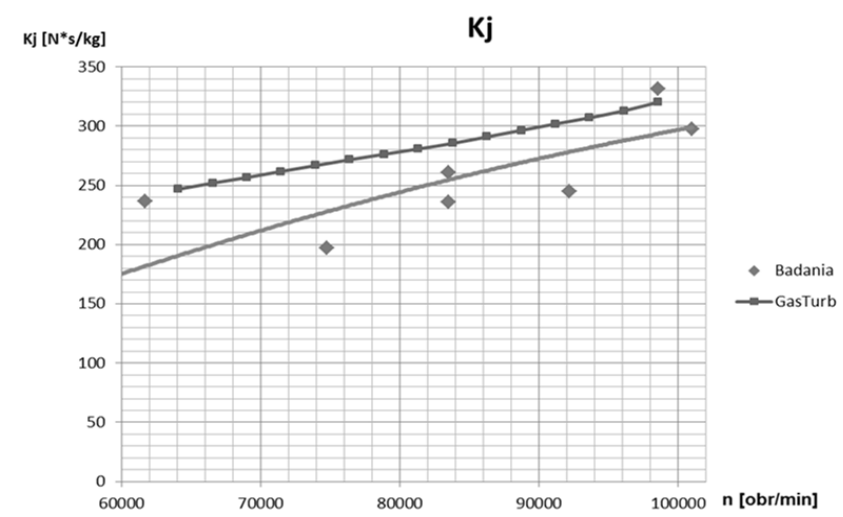

Fig. 6. Specific thrust as a function of engine rotational speed

Figure 6 presents a comparison of the curves of the specific thrust in relation to the engine rotational speed. In both cases, the curves are similar. It is noteworthy that there was a significant spread of the laboratory tests results, which may have been caused by the measurement method. The specific thrust in the laboratory tests is measured indirectly. Its values are determined based on the thrust and the mass airflow. The results of the mass airflow were characterized by a significant spread, which had impact on the $\mathrm{k}_{\mathrm{j}}$ curve.

When analyzing the curves of the changes of the specific fuel consumption (Fig. 7), one can observe that the curve generated by GasTurb decreases much faster than the actual one. The curves cross at the point corresponding to the 
engine speed of $94000 \mathrm{rpm}$ and above that value they are highly convergent. At lower engine rotational speeds, the specific fuel consumption is much more divergent. This results from the fact that the gas-dynamic calculations were carried out for the engine speed of 98000 [rpm], while the quantities impacting the fuel consumption in the miniature model may vary along with the engine speed a bit differently compared to the full size counterpart bearing in mind that the adopted measurement methods were developed based on the full size versions.

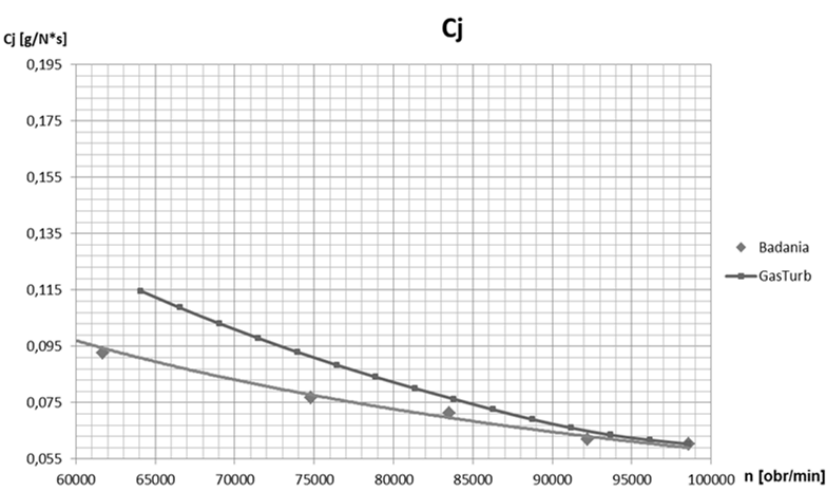

Fig. 7. Specific fuel consumption as a function of engine rotational speed

\section{Comparison of the research results with the calculations}

Figure 8 presents the comparison of the results of the GasTurb and the analytical calculations with the results for selected engine operating points. When analyzing the bar graph, one may observe that the greatest divergence between the calculations and the experiment is for the thrust. In this case, a smaller error occurs for the analytical calculations (Table 1) and amounts to $2.6 \%$, while for the GasTurb it is $3.46 \%$. The thrust calculated analytically is greater than that measured on the laboratory test stand and the thrust generated by the software is lower. This is caused by the fact that the results of the measured and calculated values of thrust were different as well. The thrust calculated analytically at a given operating point is greater than the actual one by $3.95 \mathrm{~N}$, while the GasTurb result is lower by $2.8 \mathrm{~N}$. This gives a relative error of $5.06 \%$ and $3.59 \%$ respectively. These differences may be caused by the fact that in both cases such quantities as the efficiency of individual subcomponents is not precisely known. The coefficients were selected based on the subsequent iterations so that the calculations were coherent and logical and any deviations from the real engine as little as possible. The lower value of the thrust generated by GasTurb may result from the fact that when the software is in the computing mode, it allows for more factors influencing the engine thermal cycle.

Another calculated value that rather significantly deviates from the results of the experiment is the temperature $T_{2}$ downstream of the compressor. In this case, however, the results of both the software and the analytical calculations are very similar. The difference of the order of $3.4 \%$ from the actual value may be caused by the unknown flow losses in the flow channel. Both these factors were not allowed for in the calculations on this level of detail.
The smallest deviation from the actual value occurred when calculating the total pressure $\mathrm{P}_{2}^{*}$ downstream of the compressor. For the calculations, the compression rate of the compressor and its efficiency were selected through iteration, each time comparing the outcome with the test results. Such a small divergence may confirm that the said parameters (compression rate and efficiency) were properly selected.

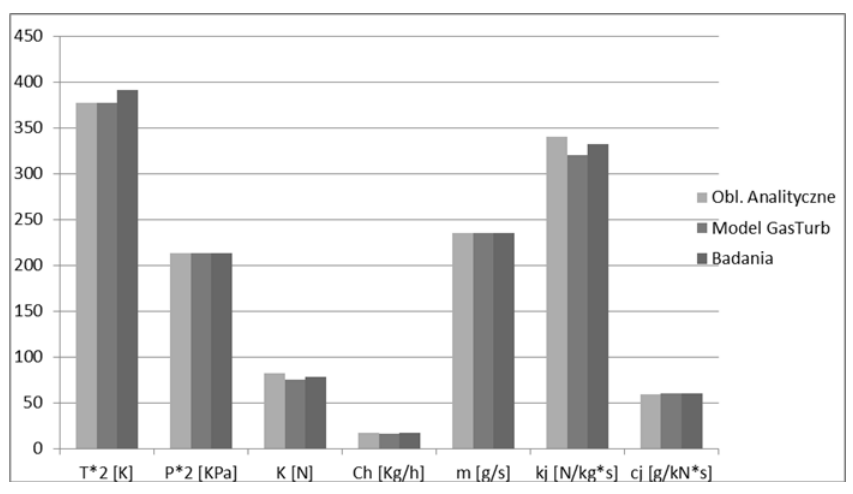

Fig. 8 Comparison of the calculations with the test results

The smallest deviation from the actual value occurred when calculating the total pressure $\mathrm{P}_{2}^{*}$ downstream of the compressor. For the calculations, the compression rate of the compressor and its efficiency were selected through iteration, each time comparing the outcome with the test results. Such a small divergence may confirm that the said parameters (compression rate and efficiency) were properly selected.

Table 1 Error values for individual parameters for selected operating point

\begin{tabular}{|l|c|c|c|c|}
\hline Parameter & $\begin{array}{c}\Delta \\
\text { Analytical } \\
\text { calculations }\end{array}$ & $\begin{array}{c}\mathrm{X} \% \\
\text { Analytical } \\
\text { calculations }\end{array}$ & $\begin{array}{c}\Delta \\
\text { GasTurb }\end{array}$ & $\begin{array}{c}\text { X\% } \\
\text { GasTurb }\end{array}$ \\
\hline $\mathrm{T}_{2}^{*}[\mathrm{~K}]$ & 13.18 & 3.37 & 13.24 & 3.39 \\
\hline $\mathrm{P}_{2}^{*}[\mathrm{KPa}]$ & 0.19 & 0.09 & 0.20 & 0.09 \\
\hline $\mathrm{K}[\mathrm{N}]$ & 3.95 & 5.06 & 2.80 & 3.59 \\
\hline $\mathrm{C}_{\mathrm{h}}[\mathrm{Kg} / \mathrm{h}]$ & 0.41 & 2.44 & 0.58 & 3.45 \\
\hline $\mathrm{m}[\mathrm{g} / \mathrm{s}]$ & 0.19 & 0.08 & 0.19 & 0.08 \\
\hline $\mathrm{k}_{\mathrm{j}}[\mathrm{N} / \mathrm{kg} \cdot \mathrm{s}]$ & 8.78 & 2.65 & 11.47 & 3.46 \\
\hline $\mathrm{c}_{\mathrm{j}}[\mathrm{g} / \mathrm{kN} \cdot \mathrm{s}]$ & 1.51 & 2.50 & 0.06 & 0.10 \\
\hline
\end{tabular}

\section{Conclusions}

The above analysis allowed a comparison of the calculations of the created engine model and its characteristics with the data obtained in the tests on a real engine. The task was rather difficult because the related literature is scarce [4].

During the works, the authors generated a computer model close to a real engine and performed proper gasdynamic calculations. As we can see in the above comparison, the results obtained in the analytical method are very similar to those obtained in the computer calculations and the deviations from the real model are on a similar level for both methods. The deviations may be caused by the model engine (GTM 120) imperfections or inadequacy of the selected calculation methods for this type of engine.

The performance parameters of the GTM 12 engine are comparable to other engines in this class. Analyses of the performance parameters of other engines have been presented in [6]. The performed works also confirmed the 
compliance of the engine cycle with the theoretical assumptions related to aviation engines. For a more in-depth analysis, additional investigations must be carried out along with detailed calculations including the geometry of the object, which would validate the above assumptions. Lack of detailed validation, despite a rather high convergence of the calculations with the results of the experiment hints treating the presented characteristics and results rather illustratively. Nevertheless, the aim of the work was fulfilled and this area in aviation propulsion should be treated as interesting and worthy of notice. It would be interesting to perform investigations of several different engines of similar design to validate the applicability of the presented theories, thus creating a trustworthy source of scientific information.

\section{Bibliography}

[1] CICHOSZ, E., KORDZIŃSKI, W., ŁYŻWIŃSKI, M. et al. Napędy lotnicze. Charakterystyka i zastosowanie. Warszawa: WKiE 1980.

[2] DZIERŻANOWSKI, P., KORDZIŃSKI, W., ŁYŻWIŃSKI, M. et al. Turbinowe silniki odrzutowe. Warszawa, WKiE 1983.

[3] DZIERŻANOWSKI, P., OTYŚ, J., SZCZECIŃSKI, S. et al. Konstrukcja silników lotniczych. Projektowanie przejściowe i dyplomowe. Warszawa, Wydziat Wydawniczy WAT 1972.
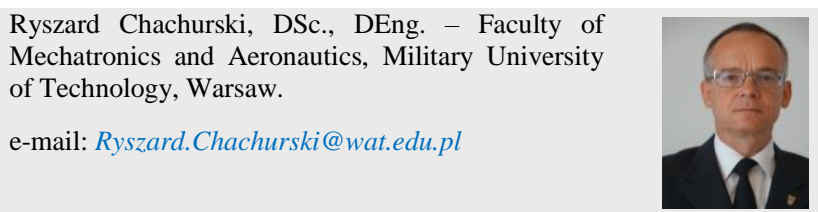

Bartosz Jędrowiak, MEng. - Faculty of Mechanical Engineering, Łódz University of Technology.

e-mail: BartoszJedrowiak@gmail.com
[4] GIERAS, M. Miniaturowe silniki turboodrzutowe. Warszawa, Oficyna Wydawnicza Politechniki Warszawskiej 2016.

[5] KAU, H-K. Optimization of a model jet engine. Institute of Flight Propulsion, Technische Universitat Munchen 2009.

[6] TRZECIAK, A. Odtworzenie parametrów obiegu i wyznaczenie osiągów i charakterystyk turbinowego silnika odrzutowego GTM 120. Praca dyplomowa. WAT Warszawa 2012.

[7] www.gasturb.de; accessed 01.2012.

[8] www.jetpol.tech; accessed 01.2012.
Adrian Trzeciak, MEng. - Faculty of Power and Aeronautical Engineering, Warsaw University of Technology.

e-mail: Adrian.Trzeciak@itc.pw.edu.pl
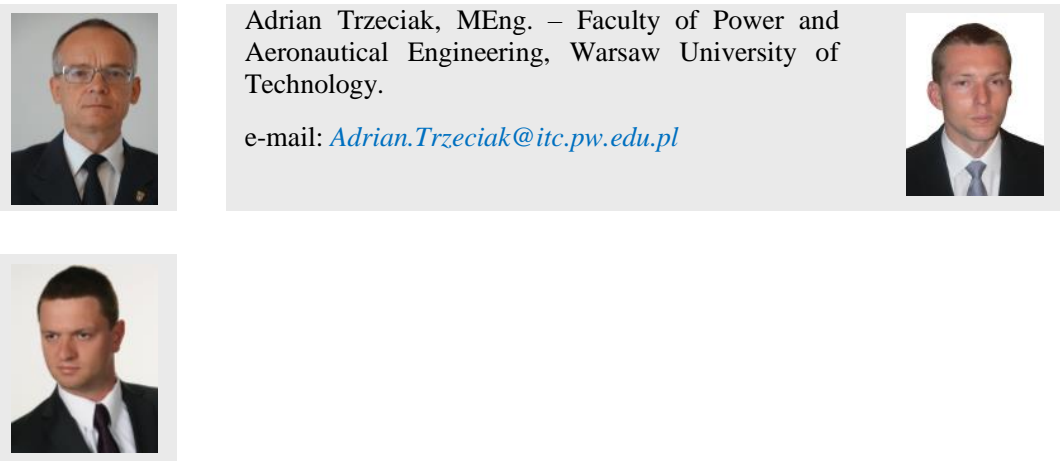